\title{
A Method Based on Only Currents for Determining Fault Direction in Radial Distribution Networks Integrated with Distributed Generations
}

\author{
Ngo Minh Khoa*, Tran Xuan Khoa \\ Faculty of Engineering and Technology, Quy Nhon University, Binh Dinh, Vietnam \\ Received 05 September 2021; received in revised form 12 December 2021; accepted 13 December 2021
}

DOI: https://doi.org/10.46604/peti.2021.8420

\begin{abstract}
Nowadays, more distributed generations (DGs) are connected to a radial distribution network, so conventional overcurrent relays cannot operate correctly when a fault occurs in the network. This study proposes a method to determine the fault direction in a three-phase distribution network integrated with DGs. The obtained pre-fault and fault currents are utilized to extract their phasors by the fast Fourier transform, and the phase angle difference between the positive-sequence components of the pre-fault and fault currents is used. Moreover, the method only uses the local current measurement to calculate and identify the phase angle change of the fault current without using the voltage measurement. Matlab/Simulink software is used to simulate the three-phase distribution network integrated with DGs. The faults with different resistances are assumed to occur at backward and forward fault locations. The simulation results show that the proposed method correctly determines the fault direction.
\end{abstract}

Keywords: directional protection relay, distributed generation, fault direction, positive-sequence current, radial distribution network

\section{Introduction}

Integrating distributed generations (DGs) into a radial distribution network has many significant benefits, such as reducing the total power loss, improving the voltage quality, etc. However, there are some existing problems on a radial distribution network integrated with DGs, i.e., the power flow, control, operation, reliability, security, and protection problem of the network [1-2]. An adaptive quantum-inspired evolutionary algorithm was then proposed to improve the power flow and voltage profile in the distribution network integrated with DGs [3-6]. In addition, the protection problem of the distribution network integrated with DGs is studied in many works [7-10].

Conventional overcurrent protection relays are usually used to protect a radial distribution network. Many researchers only use the current measurement at the relays via current transformers (CTs) to operate when the current measurement exceeds the pickup values set in the relays. Because the power flow of the distribution network integrated with DGs is changed depending on the penetration level of the network sources, the conventional overcurrent protection relays will not correctly determine the fault direction when a fault occurs in the network [7].

In Horak's work [8], a scheme of directional overcurrent relays was designed based on the phase relationship of voltages and currents at the relay location to determine the fault direction. In the work of Jang et al. [9], an adaptive approach for relay protection was applied to a distribution network integrated with a wind farm. The method proposed in Eissa's work [10]

* Corresponding author. E-mail address: ngominhkhoa@ qnu.edu.vn 
utilized a novel current polarized directional element technique to determine the fault direction on a transmission line. To completely overcome the protection problem, the directional overcurrent protection relays are applied to ensure the selection factor of the relays in the situation.

For the directional overcurrent protection relays, the direction of the fault current flowing through the relay location is determined by using the phase angle of voltage and current. The voltage polarity is used as a reference value for determining the fault direction [11]. Therefore, voltage transformers are utilized to transfer the high voltage on the primary side to the low voltage on the secondary side and to feed the protection relays. Similarly, CTs are simultaneously utilized to feed the small-scale currents to the relays. In general, when a short circuit occurs in the network, the fault current phasors at the relays are usually located in two distinct areas: the forward location and the backward location, as shown in Fig. 1. This study will exploit the information from these two areas to develop an innovative method for determining the fault direction in a radial distribution network integrated with DGs.

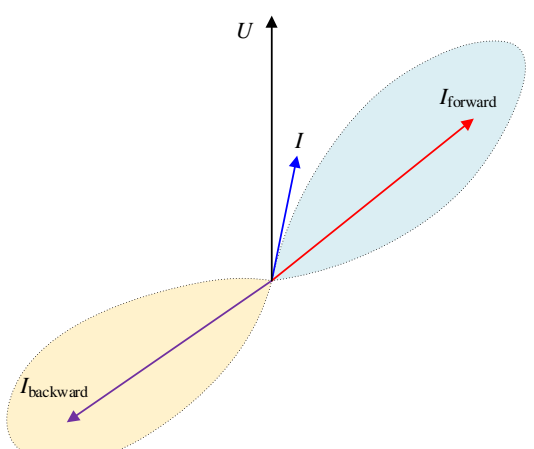

Fig. 1 Two fault identification areas for directional overcurrent protection relays

Motivated by the above-mentioned works, an innovative method is developed in this study for determining the fault direction in a radial distribution network integrated with DGs. In summary, the main contributions of this study cover three aspects: $(i)$ the proposed method only uses the current measurement at the relay location to determine the phase angle difference between the positive components of the pre-fault and fault currents; (ii) the proposed method is embedded in a relay to detect and protect all types of faults that occur in a radial distribution network integrated with DGs, including phase-to-ground (LG) faults, phase-to-phase (LL) faults, two-phase-to-ground (LLG) faults, and three-phase-to-ground (LLLG) faults; and (iii) the proposed method is more cost-effective for investing in voltage transformers, as compared to the conventional methods.

The rest of this study is organized as follows. Section 2 presents the literature review. Section 3 describes the background methodology of the proposed method for determining the fault direction in a radial distribution network integrated with DGs. The simulation results and discussion are contained in section 4, and finally section 5 concludes this study.

\section{Literature Review}

Several published works are related to the methods applied to directional overcurrent protection relays in power systems [12-18]. Voima et al. [12] presented an adaptive protection scheme to protect the medium voltage networks integrated with DGs, particularly in island operation modes. Ukil et al. [13] proposed a novel approach to detect the possibility of fault direction using only the currents at the relays. Yousfi et al. [14] developed a method based on the Adaline neural network and the instantaneous power theory for extracting the online symmetrical components and phase angle from the fault current. Eissa [15] proposed a new technique for directional overcurrent protection based on the post-fault current signals and directional reference current signals. The voltage measurement at the relays did not require determining the fault direction in the technique. 
Furthermore, Samet et al. [16] developed a high-speed algorithm for determining the fault current, which only used the current measurement at the relays. In the algorithm, the sign of the summation of multiplied faults by the samples of pre-fault current and the direction of power flow in a normal power system was a criterion to determine the fault direction. The effectiveness of the method was shown by the speed for determining the fault direction in less than one-eighth of the cycle of power frequency. Samet et al. [16] also proposed a novel directional overcurrent protection scheme for the distribution networks integrated with DGs. This protection scheme calculated the fault direction using a micro-genetic algorithm through numerical relays which were located on the network to protect and detect any changes in the configuration as well as recalculate the setting of directional overcurrent protection relays. On the other hand, to find the optimum relay setting for the minimum time to interrupt the power supply, Nascimento et al. [17] and Khond et al. [18] developed a new technique using the linear programming problem approach to optimize the relay setting in distribution networks.

The power flow in the distribution networks with the penetration of DGs is changed depending on the level of penetration. The adaptive and flexible algorithms for directional overcurrent protection relays were mentioned in many publications [19-25]. Brahma et al. [19] developed an adaptive protection scheme applied to directional overcurrent relays to protect the distribution networks with DGs. Balyith et al. [20] proposed another novel protection scheme without the need of communication assistance to determine the relay setting to minimize the relays' overall operating time. Zhan et al. [21] proposed a genetic algorithm for the location and sizing optimization of DGs in distribution networks by investigating their relay protection coordination.

Another adaptive overcurrent coordination scheme based on the evolution algorithm was developed in the work of Shih et al. [22] to enhance the relay sensitivity and overcome the drawbacks of DGs. Jia et al. [23] presented an improved scheme based on high-frequency impedance to manage the adaptability problem when determining the fault direction in the network with inverter-interfaced renewable energy generations. To overcome the challenges of overcurrent protection in the distribution networks integrated with DGs, the local measurement information was used to detect the operating status and the faulted section in the network [24]. In the work of Jones et al. [25], directional overcurrent relays were used to solve difficult problems for distribution feeder protection with high penetration of DGs.

Concerning the protection issue, IEEE Standard 1547-2003 [26] presents the criteria and requirements for the interconnection of DGs with power systems, and IEEE Standard P1547.4 [27] provides alternative approaches and good practices for the design, operation, and integration of DG island systems with power networks. Therefore, these two IEEE standards are considered in this work.

\section{Proposed Method for Determining Fault Direction}

\subsection{Single-phase network}

The fault direction in a radial distribution network integrated with DGs can be determined by the proposed method, which uses the phase angle difference between the pre-fault and fault currents at the protection relay location. The method is developed based on the phase angle change of the fault current compared with the pre-fault current, as shown in Fig. 2. The DG at the busbar A is connected to the grid source via two segments: Line 1 (from the busbar A to the busbar B) and Line 2 (from the busbar B to the busbar C). It is assumed that DG is generating the power to supply a load located at the busbar B and transferring it to the grid source via Line 2. Therefore, the power flow direction in the distribution network is normally from the busbar A to the busbar C. At the end B of Line 2 (from the busbar B to the busbar C), a protection relay is established to get the current from CT. The proposed method is applied to the relay to determine the fault direction when a fault occurs in the lines. Two fault locations, including the backward fault location $\left(\mathrm{F}_{1}\right)$ on Line 1 and the forward fault location $\left(\mathrm{F}_{2}\right)$ on Line 2, are investigated in the network as shown in Fig. 2. 


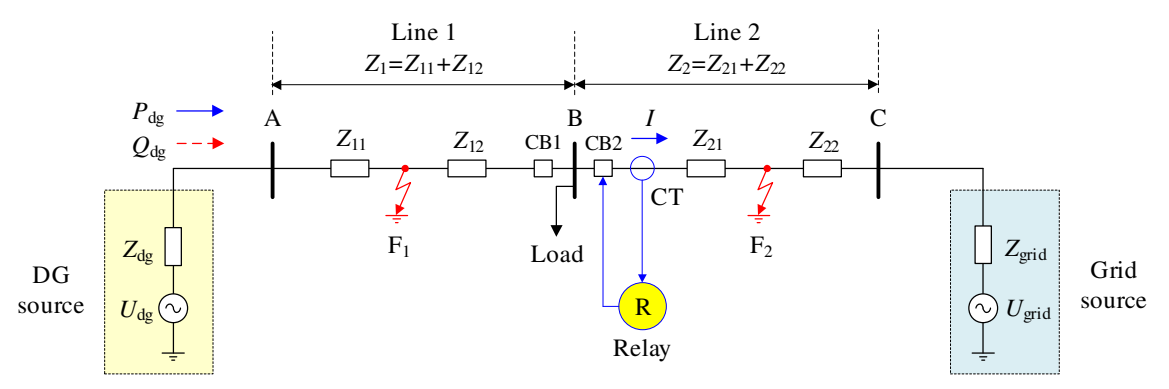

Fig. 2 Power network integrated with DGs

When a fault occurs at $F_{1}$ and $F_{2}$, the pre-fault current and the fault current are calculated as follows. The pre-fault current at the relay location is:

$$
I=\frac{U_{\mathrm{A}}-U_{\mathrm{C}}}{Z}
$$

where $U_{\mathrm{A}}$ and $U_{\mathrm{C}}$ are the voltages at the busbar A and the busbar C, respectively; $Z=Z_{1}+Z_{2}$ is the impedance from the busbar A to the busbar C.

When an LLLG fault occurs at $F_{1}$, the fault current flow from the grid side to $F_{1}$ is given as follows:

$$
I_{\mathrm{Fl}}=\frac{U_{\mathrm{C}}}{Z_{\mathrm{Fl}}}
$$

where $Z_{\mathrm{F} 1}=Z_{2}+Z_{12}$ is the impedance from the busbar $\mathrm{C}$ to $\mathrm{F}_{1}$.

Similarly, when an LLLG fault occurs at $F_{2}$, the fault current flow from DG to $F_{2}$ is given as follows:

$$
I_{\mathrm{F} 2}=\frac{U_{\mathrm{A}}}{Z_{\mathrm{F} 2}}
$$

where $Z_{\mathrm{F} 2}=Z_{1}+Z_{21}$ is the impedance from the busbar A to $\mathrm{F}_{2}$.

When a fault occurs at $F_{1}$ and $F_{2}$, the fault current flow through CT is determined as follows:

$$
I_{1}=I-I_{\mathrm{F} 1}
$$

Substituting Eqs. (1) and (2) into Eq. (4), the following equations are established:

$$
\begin{aligned}
& I_{1}=\frac{U_{\mathrm{A}}-U_{\mathrm{C}}}{Z}-\frac{U_{\mathrm{C}}}{Z_{\mathrm{F} 1}} \\
& I_{2}=I+I_{\mathrm{F} 2}
\end{aligned}
$$

Substituting Eqs. (1) and (3) into Eq. (6), the following equation is established:

$$
I_{2}=\frac{U_{\mathrm{A}}-U_{\mathrm{C}}}{Z}+\frac{U_{\mathrm{A}}}{Z_{\mathrm{F} 2}}
$$

It is assumed that the voltage at the busbar $\mathrm{A}\left(U_{\mathrm{A}}\right)$ and the voltage at the busbar $\mathrm{C}\left(U_{\mathrm{C}}\right)$ have the same voltage magnitude and phase angle. $\mathrm{F}_{1}$ and $\mathrm{F}_{2}$ are assumed at the busbar $\mathrm{A}$ and the busbar $\mathrm{C}$, respectively. The fault impedances $Z_{\mathrm{F} 1}$ and $Z_{\mathrm{F} 2}$ are equal to the impedance of the network $Z$. From Eqs. (5) and (7), it is obvious that the currents $I_{1}$ and $I_{2}$ are opposite phase angles. In general, the relationship between these currents is depicted in Fig. 3. 


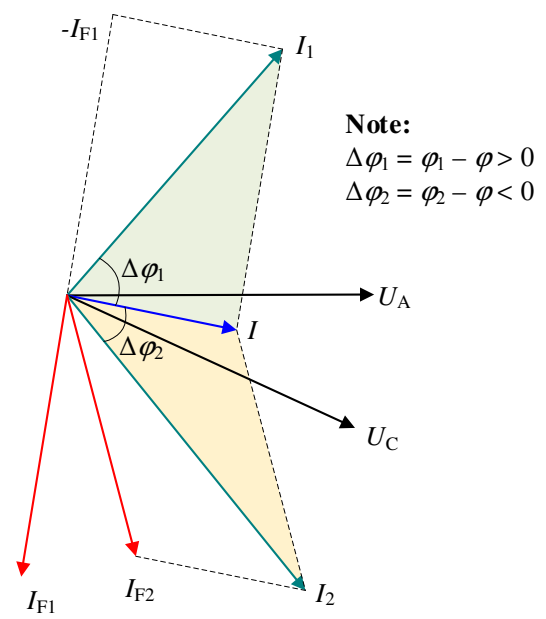

Fig. 3 Vector diagram representing the relationship among the currents $I_{1}, I_{2}$, and $I$

As can be seen in Fig. 3, the phase angle difference between the pre-fault current and the fault current is positive $\left(\Delta \varphi_{1}>0\right)$ when a fault occurs at $F_{1}$. Reversely, the phase angle difference between the pre-fault current and the fault current is negative $\left(\Delta \varphi_{2}<0\right)$ when a fault occurs at $\mathrm{F}_{2}\left(\Delta \varphi_{2}<0\right)$.

$$
\begin{aligned}
& \Delta \varphi_{1}=\varphi_{1}-\varphi>0 \\
& \Delta \varphi_{2}=\varphi_{2}-\varphi<0
\end{aligned}
$$

\subsection{Three-phase network}

For a three-phase power network, four types of faults (i.e., LG, LL, LLG, and LLLG faults) can appear in the network [28-30]. Therefore, to perform fault analysis in the network as shown in Fig. 2, a positive equivalent rule is used to calculate the fault current flow at $F_{1}$ and $F_{2}$. The positive-sequence equivalent diagrams for the fault locations at $F_{1}$ and $F_{2}$ are illustrated in Figs. 4(a) and (b), respectively, where the additional impedance $Z_{\Delta}$ depends on the fault types shown in Table 1 . The proposed method for determining the fault direction in the distribution network integrated with DGs can be described as follows:

Step 1: Faults are detected by comparing the fault current with the pickup current at the relay.

Step 2: The pre-fault and fault currents at the protection relay location are acquired.

Step 3: The phasors of the pre-fault and fault currents are estimated by using the fast Fourier transform.

Step 4: The positive-sequence current components are computed from the phasors.

Step 5: The phase angle difference is calculated.

Step 6: The fault direction is determined according to the positive equivalent rule.

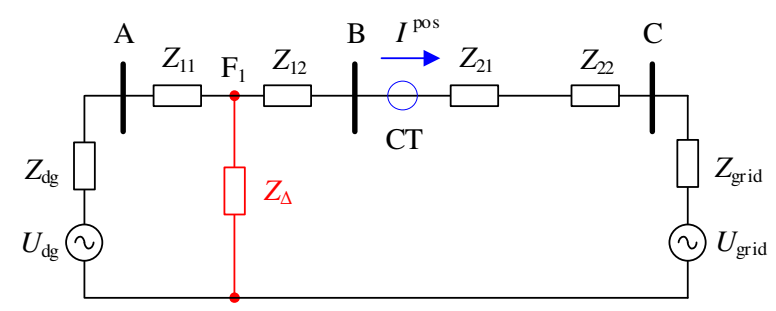

(a) For the fault at $F_{1}$

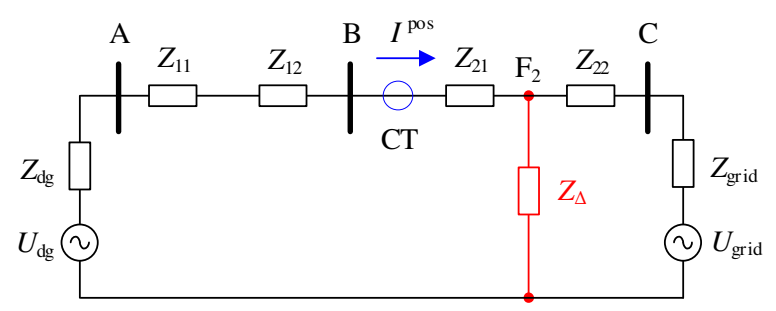

(b) For the fault at $\mathrm{F}_{2}$

Fig. 4 Positive-sequence equivalent circuit to calculate fault types 
Table 1 Additional impedance of four fault types

\begin{tabular}{|c|c|c|}
\hline Fault location & Fault type & Additional impedance $\mathrm{Z}_{\Delta}$ \\
\hline \multirow{4}{*}{$\mathrm{F}_{1}$} & LG & $Z_{\Delta}=\frac{\left(Z_{\mathrm{dg}}^{\text {zero }}+Z_{11}^{\text {zero }}\right)\left(Z_{12}^{\text {zero }}+Z_{2}^{\text {zero }}+Z_{\text {grid }}^{\text {zero }}\right)}{\left(Z_{\mathrm{dg}}^{\text {zero }}+Z_{11}^{\text {zero }}\right)+\left(Z_{12}^{\text {zero }}+Z_{2}^{\text {zero }}+Z_{\text {grid }}^{\text {zero }}\right)}+\frac{\left(Z_{\mathrm{dg}}^{\text {neg }}+Z_{11}^{\text {neg }}\right)\left(Z_{12}^{\text {neg }}+Z_{2}^{\text {neg }}+Z_{\text {grid }}^{\text {neg }}\right)}{\left(Z_{\mathrm{dg}}^{\text {neg }}+Z_{11}^{\text {neg }}\right)+\left(Z_{12}^{\text {neg }}+Z_{2}^{\text {neg }}+Z_{\text {grid }}^{\text {neg }}\right)}$ \\
\hline & LL & $Z_{\Delta}=\frac{\left(Z_{\mathrm{dg}}^{\mathrm{neg}}+Z_{11}^{\mathrm{neg}}\right)\left(Z_{12}^{\mathrm{neg}}+Z_{2}^{\mathrm{neg}}+Z_{\text {grid }}^{\text {neg }}\right)}{\left(Z_{\mathrm{dg}}^{\mathrm{neg}}+Z_{11}^{\mathrm{neg}}\right)+\left(Z_{12}^{\mathrm{neg}}+Z_{2}^{\mathrm{neg}}+Z_{\text {grid }}^{\text {neg }}\right)}$ \\
\hline & LLG & 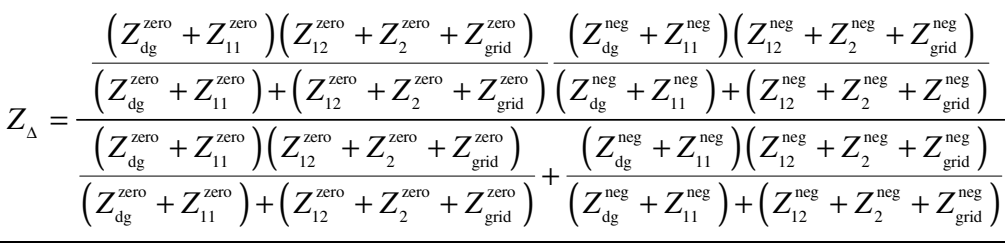 \\
\hline & LLLG & $Z_{\Delta}=0$ \\
\hline \multirow{4}{*}{$\mathrm{F}_{2}$} & LG & $Z_{\Delta}=\frac{\left(Z_{\mathrm{dg}}^{\text {zero }}+Z_{1}^{\text {zero }}+Z_{21}^{\text {zero }}\right)\left(Z_{22}^{\text {zero }}+Z_{\text {grid }}^{\text {zero }}\right)}{\left(Z_{\mathrm{dg}}^{\text {zero }}+Z_{1}^{\text {zero }}+Z_{21}^{\text {zero }}\right)+\left(Z_{22}^{\text {zero }}+Z_{\text {grid }}^{\text {zero }}\right)}+\frac{\left(Z_{\mathrm{dg}}^{\text {neg }}+Z_{1}^{\text {neg }}+Z_{21}^{\text {neg }}\right)\left(Z_{22}^{\text {neg }}+Z_{\text {grid }}^{\text {neg }}\right)}{\left(Z_{\mathrm{dg}}^{\text {neg }}+Z_{1}^{\text {neg }}+Z_{21}^{\text {neg }}\right)+\left(Z_{22}^{\text {neg }}+Z_{\text {grid }}^{\text {neg }}\right)}$ \\
\hline & LL & $Z_{\Delta}=\frac{\left(Z_{\mathrm{dg}}^{\mathrm{neg}}+Z_{1}^{\mathrm{neg}}+Z_{21}^{\mathrm{neg}}\right)\left(Z_{22}^{\mathrm{neg}}+Z_{\text {grid }}^{\text {neg }}\right)}{\left(Z_{\mathrm{dg}}^{\mathrm{neg}}+Z_{1}^{\mathrm{neg}}+Z_{21}^{\mathrm{neg}}\right)+\left(Z_{22}^{\text {neg }}+Z_{\text {grid }}^{\text {neg }}\right)}$ \\
\hline & LLG & 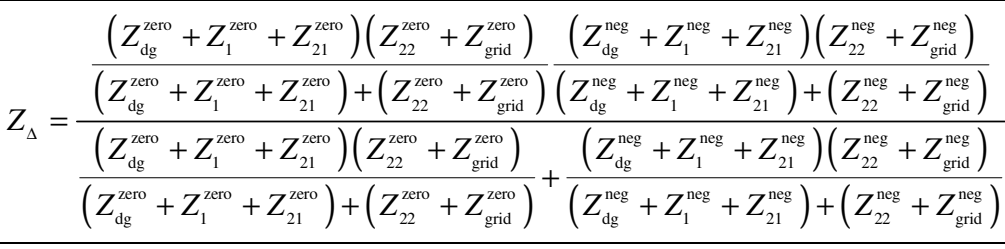 \\
\hline & LLLG & $Z_{\Delta}=0$ \\
\hline
\end{tabular}

\section{Simulation Results}

To evaluate the effectiveness of the proposed method, the three-phase power network presented in Fig. 2 is simulated using the Matlab/Simulink software. The parameters of the power network elements are given in Table 2. The nominal frequency of the network is $50 \mathrm{~Hz}$, and the nominal voltage is $22 \mathrm{kV}$. Four types of faults, including LG, LL, LLG, and LLLG faults, are emulated at $F_{1}$ and $F_{2}$, respectively. It is assumed that each fault is started at the time of 0.1 seconds, and the total simulation time is set at 0.3 seconds. Besides, the fault resistance at the fault locations is established at different values to analyze the performance of the proposed method. The simulation results of the fault current at the relay location are performed in the time domain.

Table 2 Parameters of the three-phase power network

\begin{tabular}{|c|c|}
\hline Element & Parameters \\
\hline DG source & $\begin{array}{l}\text { The frequency } f=50 \mathrm{~Hz} \\
\text { The voltage } U=1.05 \times 22 \mathrm{kV} \\
\text { The short-circuit power } S_{\mathrm{N}}=300 \mathrm{MVA} \\
\text { The positive-sequence impedance } z_{1}=0.1613+\mathrm{j} 0.0051 \Omega \\
\text { The zero-sequence impedance } z_{0}=0.4840+\mathrm{j} 0.0154 \Omega\end{array}$ \\
\hline Grid source & $\begin{array}{l}\text { The frequency } f=50 \mathrm{~Hz} \\
\text { The voltage } U=1.05 \times 22 \mathrm{kV} \\
\text { The short-circuit power } S_{\mathrm{N}}=500 \mathrm{MVA} \\
\text { The positive-sequence impedance } z_{1}=0.0968+\mathrm{j} 0.0031 \Omega \\
\text { The zero-sequence impedance } z_{0}=0.2904+\mathrm{j} 0.0092 \Omega\end{array}$ \\
\hline Line $\mathrm{AB}$ & $\begin{array}{l}\text { The line length } L=25 \mathrm{~km} \\
\text { The positive-sequence impedance } z_{1}=0.1153+0.3299 \Omega / \mathrm{km} \\
\text { The zero-sequence impedance } z_{0}=0.413+1.0430 \Omega / \mathrm{km}\end{array}$ \\
\hline Line BC & $\begin{array}{l}\text { The line length } L=25 \mathrm{~km} \\
\text { The positive-sequence impedance } z_{1}=0.1153+0.3299 \Omega / \mathrm{km} \\
\text { The zero-sequence impedance } z_{0}=0.413+1.0430 \Omega / \mathrm{km}\end{array}$ \\
\hline Load & $\begin{array}{l}\text { The nominal voltage } U=22 \mathrm{kV} \\
\text { The power rating } P=10 \mathrm{MW} \\
\text { The power factor } p f=1.0\end{array}$ \\
\hline
\end{tabular}


The fault current in a circuit is changed from the original values in a steady-state operating mode to the faulty ones. Thus, to carry out the fault simulations in this section, the steady-state voltages and currents of the network are calculated by the power flow of the network. It is assumed that DG is generating the power to the grid source via Line 1 and Line 2 . The steady-state results of the distribution network are shown in Table 3. It is obvious that the voltages at the three busbars are $1.042 \mathrm{pu}, 0.9436 \mathrm{pu}$, and $1.043 \mathrm{pu}$, respectively. The current measurement at the overcurrent relay at the busbar B is the magnitude of $0.3599 \mathrm{pu}$ and the phase angle of $42.39^{\circ}$. After establishing the initial steady-state values as shown in Table 3 , fault simulations are carried out to verify the proposed method above. The simulation results for the two fault locations $\left(\mathrm{F}_{1}\right.$ on Line 1 and $\mathrm{F}_{2}$ on Line 2) are simulated and analyzed as follows.

Table 3 Steady-state results of the distribution network

\begin{tabular}{|c|c|c|c|c|c|c|}
\hline \multirow{2}{*}{ Bus name } & \multicolumn{3}{|c|}{ Voltage } & \multicolumn{3}{c|}{ Current } \\
\cline { 2 - 7 } & $U_{\mathrm{a}}(\mathrm{pu})$ & $U_{\mathrm{b}}(\mathrm{pu})$ & $U_{\mathrm{c}}(\mathrm{pu})$ & $I_{\mathrm{a}}(\mathrm{pu})$ & $I_{\mathrm{b}}(\mathrm{pu})$ & $I_{\mathrm{c}}(\mathrm{pu})$ \\
\hline Busbar A & $1.042 \angle-2.028^{\circ}$ & $1.042 \angle-122^{\circ}$ & $1.042 \angle 118^{\circ}$ & $1.132 \angle-7.822^{\circ}$ & $1.132 \angle-127.8^{\circ}$ & $1.132 \angle-112.2^{\circ}$ \\
\hline Busbar B & $0.9436 \angle-25.1^{\circ}$ & $0.9436 \angle-145.1^{\circ}$ & $0.9436 \angle-94.9^{\circ}$ & $0.3599 \angle 42.39^{\circ}$ & $0.3599 \angle-77.61^{\circ}$ & $0.3599 \angle 162.4^{\circ}$ \\
\hline Busbar C & $1.043 \angle-29.84^{\circ}$ & $1.043 \angle-149.8^{\circ}$ & $1.043 \angle 90.16^{\circ}$ & $0.3563 \angle 42.19^{\circ}$ & $0.3563 \angle-77.81^{\circ}$ & $0.3563 \angle 162.2^{\circ}$ \\
\hline
\end{tabular}

The simulation results of the phase angle difference for $F_{1}$ on Line 1 are illustrated in Fig. 5. Figs. 5(a), (b), (c), and (d) show the results of LG faults, LL faults, LLG faults, and LLLG faults, respectively. For each case, five fault resistances (0, 5 , 10,15 , and $20 \Omega$ ) are set at the fault locations for evaluating the phase angle difference between the positive-sequence of the pre-fault current and the fault current at the relay location. It is obvious that the phase angle difference is dramatically increased from the value of 0 degrees at the time $t=0.1$ seconds. After that, it reaches a positive value. This information is used to determine the backward fault direction.

For $\mathrm{F}_{2}$ on Line 2, the phase angle difference between the positive-sequence components of the pre-fault current and the fault current is shown in Fig. 6 . In this case study, five fault resistances $(0,5,10,15$, and $20 \Omega)$ are also set at the fault locations. All the case studies are simulated in Matlab/Simulink and the results are shown in Figs. 6(a), (b), (c), and (d) for the LG faults, LL faults, LLG faults, and LLLG faults, respectively. As can be seen in Fig. 6, the phase angle difference is dramatically decreased at the time $t=0.1$ seconds. It then reaches a negative value. Therefore, the fault direction of $F_{2}$ is the forward fault direction.

In addition, the fault resistance at the two fault locations is varied from 0 to $20 \Omega$ with a step of $1 \Omega$ in each case study to evaluate the effectiveness of the proposed method. For each fault resistance, the apparent impedance from the grid source and the DG source to the fault location is also changed in both the magnitude and phase angle; these simulation results are shown in Fig. 7. As can be seen in Fig. 7, the x-axis and y-axis show the real and imaginary components of the fault current at the relay location, respectively. These simulation results show clearly that the red and blue nodes in Fig. 7 represent the forward and backward faults, respectively.

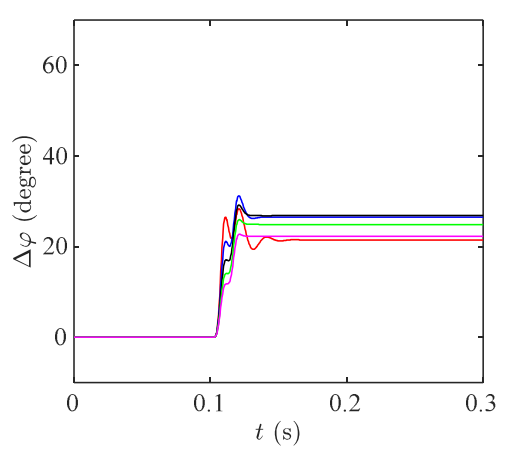

(a) LG faults
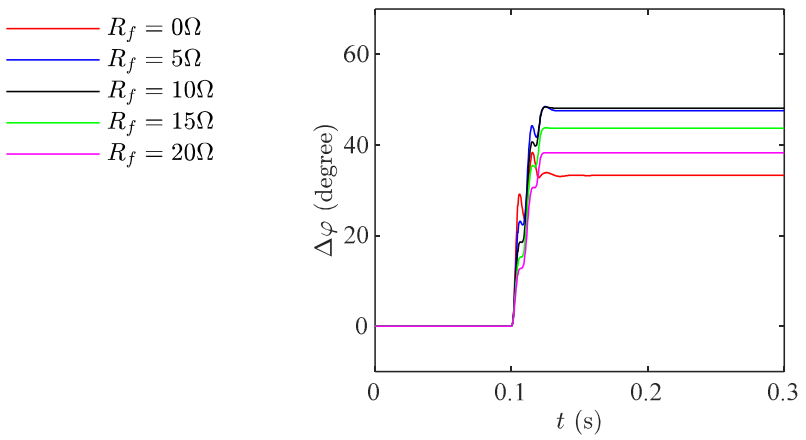

(b) LL faults

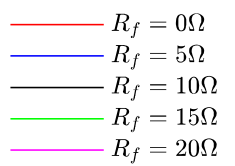

Fig. 5 Phase angle difference when faults occur at $F_{1}$ 


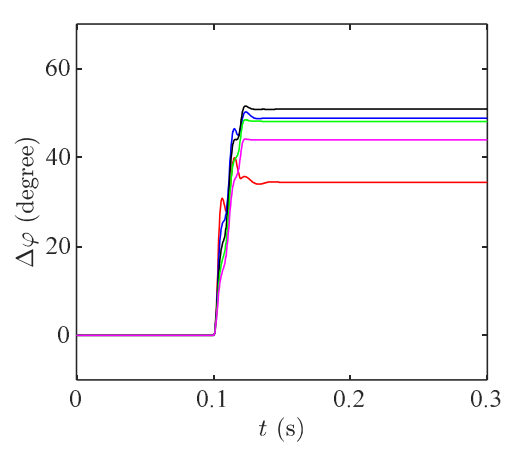

(c) LLG faults

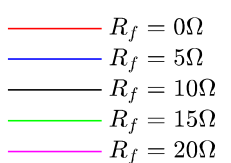

Fig. 5 Phase angle difference when faults occur at $\mathrm{F}_{1}$ (continued)

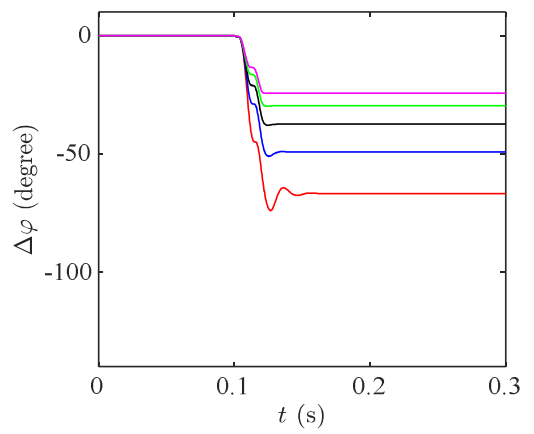

(a) LG faults

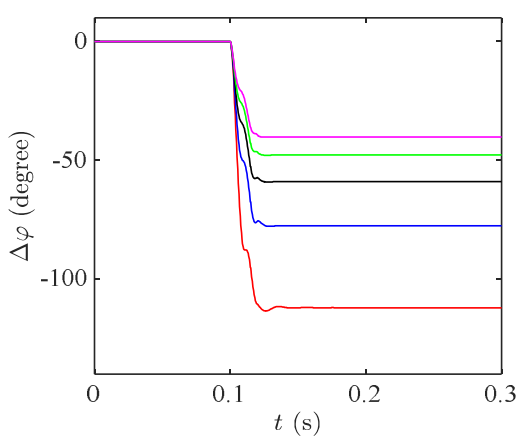

(c) LLG faults

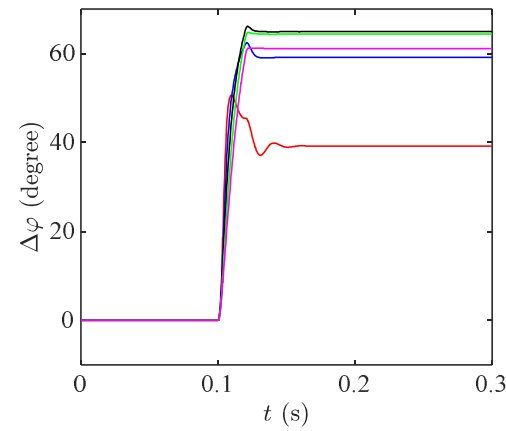

(d) LLLG faults
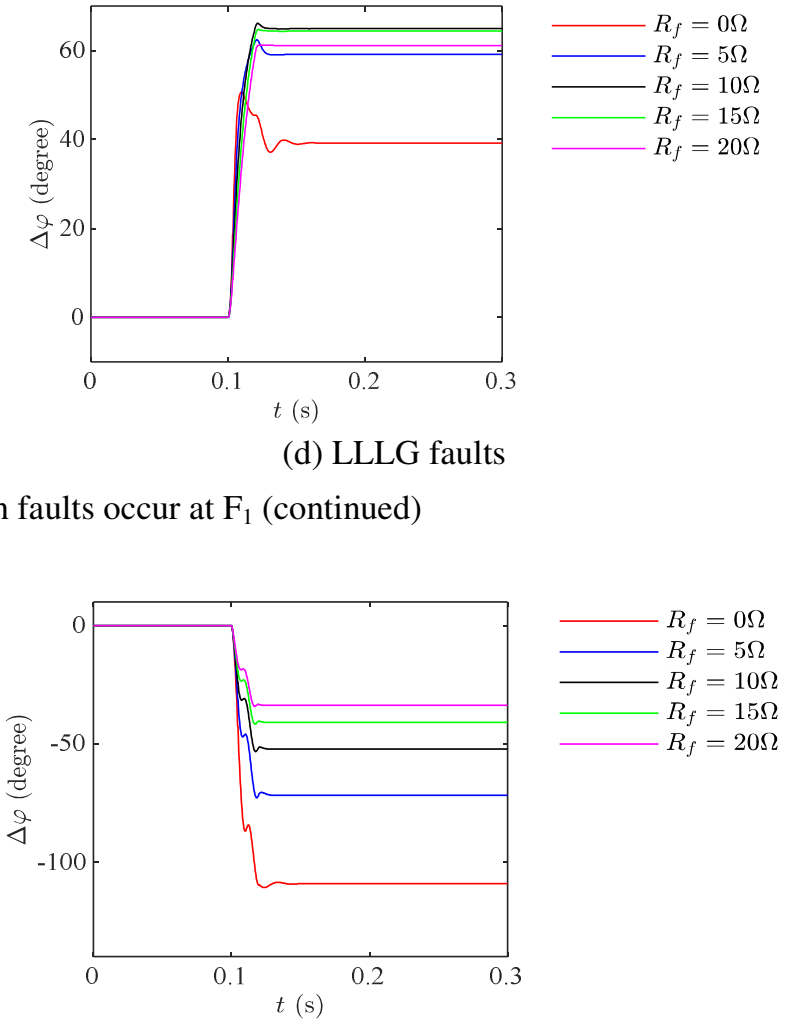

(b) LL faults

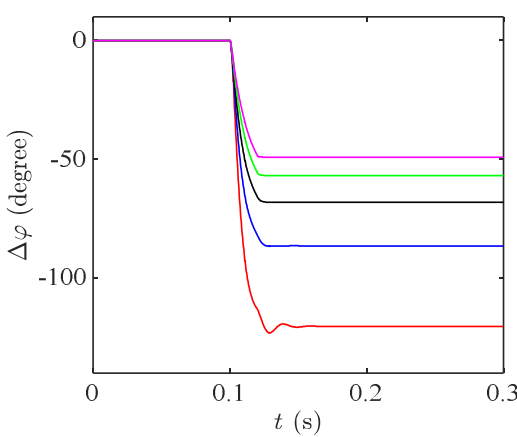

(d) LLLG faults

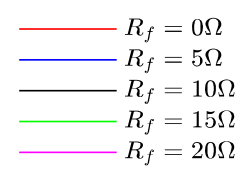

Fig. 6 Phase angle difference when faults occur at $\mathrm{F}_{2}$

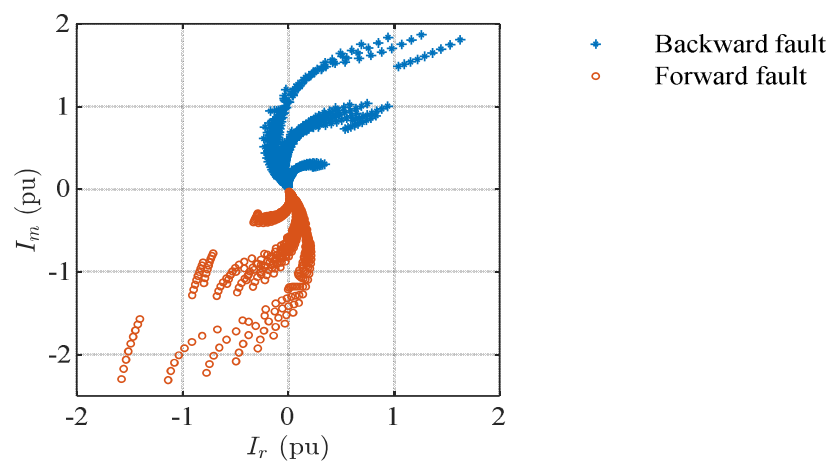

Fig. 7 Two distinct areas for the backward faults and the forward faults

\section{Discussion}

In this study, a method is developed based only on the currents at the relay location for determining the fault direction in a radial distribution network integrated with DGs. A typical radial distribution network is modeled and simulated in the Matlab/Simulink software. The power flow of steady state in the network is the necessary initial condition to determine the 
fault direction when faults occur in the network. Two fault locations, including the backward and forward locations, are considered to confirm the capability of the proposed method. For each case study, the positive-sequence components of the pre-fault and fault currents are extracted using the fast Fourier transform, and then the phase angle difference is calculated to determine the fault direction. This work also establishes four types of faults, including LG faults, LL faults, LLG faults, and LLLG faults, as well as the different fault resistances ranging from 0 to $20 \Omega$.

\section{Conclusions}

This study proposes an innovative method for determining the fault direction in a radial distribution network integrated with DGs. The fast Fourier transform is applied to extract the phasors of the pre-fault and fault currents at the relay location. The proposed method determines the fault direction based on the phase angle difference between the positive-sequence components of the pre-fault and fault currents at the relay location. The analysis results confirm that the phase angle difference is positive for the faults in the backward direction and negative for the faults in the forward direction. The effectiveness of this method is verified by performing the simulation of a three-phase radial distribution network integrated with DGs. Four types of faults with different fault resistances and locations are simulated to evaluate the method. The simulation results confirm that the protection relay applied by this method determines the fault direction correctly. Furthermore, because the proposed method only requires the local current measurement without the voltage measurement, it can be easily implemented in conventional non-directional overcurrent relays. The directional overcurrent relays applied by the proposed method can be utilized for future smart grids, displacing the traditional directional overcurrent relays that utilize the reference voltage phasors for estimating the fault direction.

\section{Conflicts of Interest}

The authors declare no conflict of interest.

\section{Nomenclature}

\begin{tabular}{|c|c|c|c|}
\hline$U_{\text {grid }}$ & Voltage of the grid source & $Z_{12}^{\text {zero }}$ & Zero-sequence impedance of the segment from $\mathrm{F}_{1}$ to $\mathrm{B}$ \\
\hline$Z_{\text {grid }}$ & Impedance of the grid source & $Z_{21}$ & Impedance of the segment from $\mathrm{B}$ to $\mathrm{F}_{2}$ \\
\hline$Z_{\text {grid }}^{\text {neg }}$ & Negative-sequence impedance of the grid source & $Z_{21}^{\text {neg }}$ & Negative-sequence impedance of the segment from $\mathrm{B}$ to $\mathrm{F}_{2}$ \\
\hline$Z_{\text {grid }}^{\text {zero }}$ & Zero-sequence impedance of the grid source & $Z_{21}^{\text {zero }}$ & Zero-sequence impedance of the segment from $\mathrm{B}$ to $\mathrm{F}_{2}$ \\
\hline$U_{\mathrm{dg}}$ & Voltage of the DG source & $Z_{22}$ & Impedance of the segment from $\mathrm{F}_{2}$ to $\mathrm{C}$ \\
\hline$P_{\mathrm{dg}}$ & Active power of the DG source & $Z_{22}^{\text {neg }}$ & Negative-sequence impedance of the segment from $\mathrm{F}_{2}$ to $\mathrm{C}$ \\
\hline$Q_{\mathrm{dg}}$ & Reactive power of the DG source & $Z_{22}^{\text {zero }}$ & Zero-sequence impedance of the segment from $\mathrm{F}_{2}$ to $\mathrm{C}$ \\
\hline$Z_{\mathrm{dg}}$ & Impedance of the DG source & $Z_{\Delta}$ & Additional impedance \\
\hline$Z_{\mathrm{dg}}^{\text {neg }}$ & Negative-sequence impedance of the DG source & $U_{\mathrm{a}}$ & Phase-a voltage \\
\hline$Z_{\mathrm{dg}}^{\text {zero }}$ & Zero-sequence impedance of the DG source & $U_{\mathrm{b}}$ & Phase-b voltage \\
\hline$Z_{11}$ & Impedance of the segment from $\mathrm{A}$ to $\mathrm{F}_{1}$ & $U_{\mathrm{c}}$ & Phase-c voltage \\
\hline$Z_{11}^{\text {neg }}$ & Negative-sequence impedance of the segment from A to $F_{1}$ & $I_{\mathrm{a}}$ & Phase-a current \\
\hline$Z_{11}^{\text {zero }}$ & Zero-sequence impedance of the segment from $A$ to $F_{1}$ & $I_{\mathrm{b}}$ & Phase-b current \\
\hline$Z_{12}$ & Impedance of the segment from $\mathrm{F}_{1}$ to $\mathrm{B}$ & $I_{\mathrm{c}}$ & Phase-c current \\
\hline$Z_{12}^{\text {neg }}$ & Negative-sequence impedance of the segment from $\mathrm{F}_{1}$ to $\mathrm{B}$ & & \\
\hline
\end{tabular}

\section{References}

[1] W. A. Elmore, Protective Relaying: Theory and Applications, 2nd ed., New York: Marcel Dekker, 2003.

[2] K. Kauhaniemi and L. Kumpulainen, "Impact of Distributed Generation on the Protection of Distribution Networks," 8th IEE International Conference on Developments in Power System Protection, pp. 315-318, April 2004. 
[3] G. Manikanta, A. Mani, H. P. Singh, and D. K. Chaturvedi, "Simultaneous Application of Distributed Generator and Network Reconfiguration for Power Loss Reduction Using an Adaptive Quantum Inspired Evolutionary Algorithm," International Journal of Energy Technology and Policy, vol. 17, no. 2, pp. 140-179, April 2021.

[4] G. Manikanta, A. Mani, H. P. Singh, and D. K. Chaturvedi, "Effect of Voltage Dependent Load Model on Placement and Sizing of Distributed Generator in Large Scale Distribution System," Majlesi Journal of Electrical Engineering, vol. 14, no. 4, pp. 97-121, December 2020.

[5] G. Manikanta, A. Mani, H. P. Singh, and D. K. Chaturvedi, “Adaptive Quantum-Inspired Evolutionary Algorithm for Optimizing Power Losses by Dynamic Load Allocation on Distributed Generators," Serbian Journal of Electrical Engineering, vol. 16, no. 3, pp. 325-357, 2019.

[6] G. Manikanta, A. Mani, H. P. Singh, and D. K. Chaturvedi, "Placing Distributed Generators in Distribution System Using Adaptive Quantum Inspired Evolutionary Algorithm," 2nd International Conference on Research in Computational Intelligence and Communication Networks, pp. 157-162, September 2016.

[7] P. B. Eriksen, T. Ackermann, H. Abildgaard, P. Smith, W. Winter, and J. R. Garcia, "System Operation with High Wind Generation," IEEE Power and Energy Magazine, vol. 3, no. 6, pp. 65-74, October 2005.

[8] J. Horak, "Directional Overcurrent Relaying (67) Concepts," 59th Annual Conference for Protective Relay Engineers, pp. 1-8, April 2006.

[9] S. I. Jang, J. H. Choi, J. W. Kim, and D. M. Choi, “An Adaptive Relaying for the Protection of a Wind Farm Interconnected with Distribution Networks," IEEE PES Transmission and Distribution Conference and Exposition, pp. 296-302, September 2003.

[10] M. M. Eissa, "Evaluation of a New Current Directional Protection Technique Using Field Data," IEEE Transactions on Power Delivery, vol. 20, no. 2, pp. 566-572, April 2005.

[11] R. V. R. De Carvalho, F. H. T. Vieira, S. G. De Araújo, and C. R. Lima, “A Protection Coordination Scheme for Smart Grid Based Distribution Systems Using Wavelet Based Fault Location and Communication Support,” IEEE PES Conference on Innovative Smart Grid Technologies, pp. 1-8, April 2013.

[12] S. Voima, H. Laaksonen, and K. Kauhaniemi, “Adaptive Protection Scheme for Smart Grids,” 12th IET International Conference on Developments in Power System Protection, pp. 1-6, April 2014.

[13] A. Ukil, B. Deck, and V. H. Shah, "Smart Distribution Protection Using Current-Only Directional Overcurrent Relay," IEEE PES Innovative Smart Grid Technologies Conference Europe, pp. 1-7, October 2010.

[14] F. L. Yousfi, D. O. Abdeslam, T. Bouthiba, N. K. Nguyen, and J. Merckle, “Adaline for Online Symmetrical Components and Phase-Angles Identification in Transmission Lines,” IEEE Transactions on Power Delivery, vol. 27, no. 3, pp. 1134-1143, June 2012.

[15] M. M. Eissa, "Current Directional Protection Technique Based on Polarizing Current,” International Journal of Electrical Power and Energy Systems, vol. 44, no. 1, pp. 488-494, January 2013.

[16] H. Samet, T. Ghanbari, M. A. Jarrahi, and H. J. Ashtiani, "Efficient Current-Based Directional Relay Algorithm," IEEE Systems Journal, vol. 13, no. 2, pp. 1262-1272, September 2018.

[17] J. P. Nascimento, N. S. D. Brito, and B. A. Souza, “An Adaptive Overcurrent Protection System Applied to Distribution Systems," Computers and Electrical Engineering, vol. 81, 106545, January 2020.

[18] S. V. Khond and G. A. Dhomane, "Optimum Coordination of Directional Overcurrent Relays for Combined Overhead/Cable Distribution System with Linear Programming Technique," Protection and Control of Modern Power Systems, vol. 4, no. 1, pp. 1-7, April 2019.

[19] S. M. Brahma and A. A. Girgis, "Development of Adaptive Protection Scheme for Distribution Systems with High Penetration of Distributed Generation," IEEE Transactions on Power Delivery, vol. 19, no. 1, pp. 56-63, January 2004.

[20] A. A. Balyith, H. M. Sharaf, M. Shaaban, E. F. El-Saadany, and H. H. Zeineldin, "Non-Communication Based Time-Current-Voltage Dual Setting Directional Overcurrent Protection for Radial Distribution Systems with DG," IEEE Access, vol. 8, pp. 190572-190581, October 2020.

[21] H. Zhan, C. Wang, Y. Wang, X. Yang, X. Zhang, C. Wu, et al., "Relay Protection Coordination Integrated Optimal Placement and Sizing of Distributed Generation Sources in Distribution Networks," IEEE Transactions on Smart Grid, vol. 7, no. 1, pp. 55-65, January 2016.

[22] M. Y. Shih, A. Conde, Z. Leonowicz, and L. Martirano, “An Adaptive Overcurrent Coordination Scheme to Improve Relay Sensitivity and Overcome Drawbacks Due to Distributed Generation in Smart Grids," IEEE Transactions on Industry Applications, vol. 53, no. 6, pp. 5217-5228, December 2017.

[23] K. Jia, Z. Yang, Y. Fang, T. Bi, and M. Sumner, "Influence of Inverter-Interfaced Renewable Energy Generators on Directional Relay and an Improved Scheme," IEEE Transactions on Power Electronics, vol. 34, no. 12, pp. 11843-11855, December 2019. 
[24] P. Mahat, Z. Chen, B. Bak-Jensen, and C. L. Bak, "A Simple Adaptive Overcurrent Protection of Distribution Systems with Distributed Generation,” IEEE Transactions on Smart Grid, vol. 2, no. 3, pp. 428-437, September 2011.

[25] D. Jones and J. J. Kumm, "Future Distribution Feeder Protection Using Directional Overcurrent Elements," IEEE Transactions on Industry Applications, vol. 50, no. 2, pp. 1385-1390, April 2014.

[26] Interconnecting Distributed Resources with Electric Power Systems, IEEE Standard 1547-2003, 2011.

[27] Draft Guide for Design, Operation, and Integration of Distributed Resource Island Systems with Electric Power Systems IEEE Standard P1547.4, 2011.

[28] IEEE Recommended Practice for Conducting Short-Circuit Studies and Analysis of Industrial and Commercial Power Systems, IEEE Standard 3002.3-2018, 2019.

[29] N. M. Khoa, N. A. Toan, and D. D. Tung, "Experimental Study on Fault Ride-Through Capability of VSC-Based HVDC Transmission System,” Archives of Electrical Engineering, vol. 70, no. 1, pp. 173-188, March 2021.

[30] N. M. Khoa and D. D. Tung, "Locating Fault on Transmission Line with Static Var Compensator Based on Phasor Measurement Unit," Energies, vol. 11, no. 9, 2380, September 2018.

Copyright $\odot$ by the authors. Licensee TAETI, Taiwan. This article is an open access article distributed under the terms and conditions of the Creative Commons Attribution (CC BY-NC) license (https://creativecommons.org/licenses/by-nc/4.0/). 